\title{
Eficiência de sanificantes alternativos sobre frutos contaminados artificialmente com Escherichia coli
}

\author{
Josidel Conceição OLIVER ${ }^{1}$. \\ Jaqueline de Lima GERMANO ${ }^{1}$ \\ Sandra Maria Oliveira Morais VEIGA ${ }^{2}$ \\ ${ }^{1}$ Graduanda em Farmácia pela Universidade Federal de Alfenas (UNIFAL-MG) \\ ${ }^{2}$ Professora Doutora na UNIFAL-MG \\ *jsdl.oliver@gmail.com
}

Recebido em: 30/10/2012 - Aprovado em: 28/12/2012 - Disponibilizado em: 30/12/2012

RESUMO: O desenvolvimento de micro-organismos patogênicos em frutos minimamente processados depende de suas características, propriedades intrínsecas e dos efeitos do processamento, embalagem e armazenamento. Os frutos minimamente processados alojam uma microbiota diversificada, frequentemente, da ordem de $10^{5}$ a $10^{7} \mathrm{UFC} / \mathrm{g}$. Neste sentido, faz-se necessário que frutos minimamente processados tenham como etapa crucial a higienização (limpeza e sanitização). O hipoclorito de sódio é o produto mais utilizado para a desinfecção de frutas e hortaliças, entretanto,vários micro-organismos vêm apresentando resistência ao cloro inorgânico e ainda, há o risco de formação de subprodutos potencialmente carcinogênicos (trihalometanos). Este trabalho teve por objetivo avaliar sanificantes alternativos para frutos artificialmente contaminados. Os sanificantes utilizados foram dicloroisocianurato de sódio (NaDCC) e ôzonio. Para avaliar a eficiência dos sanificantes, foi feita a contaminação artificial dos frutos (marolo e morango) com a cepa E. coli ATCC 25922 em suspensão de solução salina, com turvação correspondente ao tubo 10 da

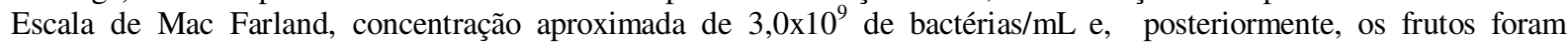
separados em grupos: controle e tratados, sendo que o tempo de contato fruto-sanificante foi de 20 minutos. As análises foram feitas segundo Silva et al. (2010) e compreenderam a determinação do Número Mais Provável (NMP) de E. coli. Os resultados obtidos foram que dentre os sanificantes estudados, o que apresentou melhor percentual de redução microbiana foi o NaDCC, apresentando reduções microbianas médias de $82,08 \%$ para o marolo (01 ciclo log) e de $98,21 \%$ para o morango (02 ciclos log).

Palavras-chave: Sanificantes alternativos. Dicloroisocianurato de sódio. Ozônio. E. coli. Contaminação artificial

\section{Efficiency of alternative sanitizers on fruits artificially contaminated with}

\section{Escherichia coli}

\begin{abstract}
The development of pathogenic microorganisms in minimally processed fruits depends on its characteristics, intrinsic properties and the effects of processing, packaging and storage. The fruits minimally processed can host a diverse microbiota, often of the order $10^{5}-10^{7} \mathrm{CFU} / \mathrm{g}$. In this sense, it is necessary for minimally processed fruit, have as crucial step hygiene (cleaning and sanitizing). Sodium hypochlorite is the most used for disinfection of fruits and vegetables, however, several micro-organisms have presented resistance to inorganic chlorine and still, there is a risk of forming potentially carcinogenic byproducts (trihalomethanes). This study aimed to evaluate alternative sanitizers in fruits artificially contaminated. The sanitizers used were sodium dichloroisocyanurate (NaDCC) and ozone. To evaluate the effectiveness of sanitizers, the fruits (strawberry and Marolo) were artificially contaminated with strains of E. coli ATCC 25922 suspended in saline, with a turbidity corresponding to the tube 10 Scale Mac Farland, approximate concentration of $3.0 \times 10^{9}$ bacteria $/ \mathrm{mL}$ and posteriorly the fruits were separated into groups: control and treatment, and the time of contact of the fruit with the sanitizer was 20 minutes. The analyzes were performed according to Silva et al. (2010) and included the determination of Most Probable Number (MPN) of E. coli. The results were that among the sanitizing studied, that showed the greatest percentage of microbial reduction was NaDCC presenting microbial reductions averages $82.08 \%$ in the Marolo (01 log cycle) and $98.21 \%$ for the strawberry ( $02 \log$ cycles).
\end{abstract}

Keywords: Alternative sanitizers. Sodium dichloroisocyanurate. Ozone. E. coli. Artificial contamination. 


\section{INTRODUÇÃO}

A lavagem e desinfecção de produtos consumidos crus são consideradas etapas particularmente críticas para a qualidade microbiológica de frutos e vegetais. Nessa fase, é importante a seleção do sanificante que, além de eficaz, deve ser também seguro do ponto de vista toxicológico (NASCIMENTO, 2003; $\quad$ FRANCO; LANDGRAF, 2003).

A sanificação é importente no processamento de alimentos, pois contribui para a redução de micro-organismos deteriorantes e patogênicos, e assim, permiti que o alimento atenda aos padrões exigidos pela legislação, aumentando a vida de prateleira e melhorando as condições higiênico-sanitária dos mesmos, evitando riscos à saúde do consumidor pela veiculação de patógenos (REIS et al., 2008).

O uso de sanificantes visa reduzir, até níveis seguros, os micro-organismos alteradores patógenos de alimentos (SANTOS, 2003).

O cloro, sob a forma de hipoclorito de sódio, tem sido o composto mais utilizado para garantir a qualidade microbiológica de água e alimentos e aumentar a segurança e a vida útil de produtos processados. Entretanto, estudos mostram que o hipoclorito de sódio pode levar à formação de subprodutos indesejáveis, como compostos organoclorados, trihalometanos (THMs) e ácidos haloacéticos, que são mutagênicos, tóxicos e carcinogênicos em água, em alimentos ou em superfícies de contato (MACEDO, 2001; PRESTES, 2007). Além disso, vários tipos de micro-organismos, tais como cepas de Escherichia coli, Salmonella typhi e Aspergillus niger têm apresentado resistência a este desinfetante (VEIGA, 2003).

Fica claro, então, que sanificantes mais potentes, mais eficazes e que, ao mesmo tempo, não levem à formação de resíduos tóxicos, precisam ser explorados. Nesta linha, o dicloroisocianurato de sódio $(\mathrm{NaDCC})$ e ozônio vêm conquistando espaço como produtos alternativos para a desinfecção de água e alimentos. A utilização deles, isolados ou em conjunto pode ser uma alternativa eficiente para a sanificação de alimentos, sem a indesejável produção de resíduos tóxicos (PELOSO 2006).

O NaDCC é um composto clorado orgânico comercializado na forma de pó ou comprimido efervescente que possui ação letal sobre os micro-organismos seja devida a cloração de proteínas celulares ou sistemas enzimáticos, pelo ácido hipocloroso não ionizado, causando hidrólise das cadeias peptídicas das membranas celulares microbianas (BLOCK, 1991; MACEDO, 2007). Este composto apresenta alta tecnologia para a sanificação em geral, podendo ser empregado para a desinfecção de água para consumo humano, frutas, verduras, 
legumes, de artigos e superfícies que entram em contato com alimentos (MACEDO, 2001).

A Resolução ${ }^{\circ} 150$, de maio de 1999 , da Anvisa autoriza a inclusão do ácido dicloroisocianúrico e seus sais de sódio e potássio, como princípio ativo para uso em formulações de produtos destinados a desinfecção de água para consumo humano (BRASIL, 1999). Nos EUA e Europa o NaDCC já está sendo usado em alimentos desde a década de 90, substituindo os compostos clorados inorgânicos, como o hipoclorito de sódio (MACEDO, 2001).

O ozônio $\left(\mathrm{O}_{3}\right)$, descoberto em 1839 por Schonbein, é a forma triatômica do oxigênio. É um gás instável, solúvel em água (treze vezes mais do que o oxigênio, em temperaturas de 0 a $30^{\circ} \mathrm{C}$ ) e de odor pungente (frescor), que é formado pela excitação do oxigênio molecular a oxigênio atômico em um ambiente energizado, no qual ocorre a recombinação com outras moléculas de oxigênio (RICE, 1996).

As propriedades virucidas e bactericidas do ozônio foram reconhecidas desde a $1^{\mathrm{a}}$ Guerra Mundial, quando o ozônio era aplicado topicamente para desinfetar ferimentos e queimaduras de gás mostarda (BOCCI, 2004).

No âmbito celular, oxida grupos sulfidrila e amino, coagula proteínas e inativa as enzimas catalase, peroxidase e desidrogenase causando morte celular rápida.
Em bactérias Gram negativas, as camadas de lipoproteínas e lipopolissacarídeos são os primeiros locais de destruição pelo ozônio, resultando em aumento da permeabilidade celular e eventual lise celular (KIM; YOUSEF; DAVE, 1999; NASCIMENTO et al., 2005).

Dessa forma, esta substância apresenta alta capacidade desinfetante e sanificante, amplo espectro de ação, atuando sobre bactérias, vírus, fungos filamentosos e leveduras, e sobre formas esporuladas (TORRES et a.l, 1996).

A concentração e o tempo de ação são menores que os exigidos pelo cloro. Ainda, o ozônio tem a propriedade de oxidar alguns poluentes orgânicos e inorgânicos. Além disso, ele não altera as características organolépticas da água e dos alimentos e não deixa resíduos tóxicos ou carcinogênicos nos mesmos, quando concentrações adequadas são utilizadas (TORRES et al., 1996). Assim, o ozônio é particularmente atrativo, pois pode ser aplicado na forma de gás ou dissolvido em água, e dissipa-se rapidamente, sendo o residual muito baixo ou nulo (RICHARDSON et al., 1998).

A utilização do ozônio em processamento de alimentos foi aprovada na década atual pelo Food and Drug Association, sendo recomendada para utilização em tratamento, estocagem e processamento de produtos alimentícios, conforme o título 21 , 
capítulo 1, subcapítulo D, do FDA, (FDA, 2001).

O ozônio tem numerosos potenciais de aplicações na indústria de alimentos. Sua alta reatividade e decomposição espontânea em produtos não tóxicos fazem desta substância uma alternativa viável para aumentar a segurança microbiológica de produtos alimentícios (KIM et al., 1999, apud NASCIMENTO, 2005).

A flora do cerrado possui diversas espécies frutíferas com grande potencial nutricional, o marolo é uma delas, uma fruta de sabor exótico, que apresenta bom valor comercial e alto potencial de antioxidante, além de ser rico em fibras (ROESLER et al. 2007).

O morango é um pseudofruto muito apreciado tanto pelo mercado nacional como internacional. Sua fragilidade demanda cuidados na colheita, manuseio, armazenamento, transporte, processamento e comercialização, devido aos danos mecânicos, microbiológicos e fisiológicos que podem comprometer a qualidade do fruto (PONCE, 2010).

$\mathrm{O}$ século $\mathrm{XX}$ não foi marcado apenas por avanços em tecnologia. Em função da mecanização agrícola, um elevado contingente de população do campo migrou para as cidades e, em consequiência disso, fez surgir mudanças nos hábitos alimentares, fato que vem demandando produtos mais saudáveis e com maior durabilidade. Assim, surge por volta de 1990, a técnica de processamento mínimo de alimentos; notando-se, desde então, um crescimento tanto na pesquisa como na comercialização desses produtos, em função da demanda por produtos frescos e saudáveis. Logo, o processamento mínimo proporciona maior praticidade e rapidez no preparo diário dos alimentos, uma mudança cada vez mais necessária ao agitado mundo moderno. Por outro lado agrega valor aos produtos, o que viabiliza a economia familiar (TEIXEIRA, 2001; MELO; SILVA; ALVES, 2011).

Considerando que o exposto, realizouse esta pesquisa que avalia a utilização de sanificantes alternativos sobre marolo (Annona crassiflora Mart.) e morango (Fragaria ananassa Duch) cv Oso Grande minimamente processados e contaminados com E. coli.

A contaminação por coliformes é frequentemente associada com alimentos cultivados próximos ao solo ou com o manuseio humano durante a colheita e o processamento, a E. coli é um habitante comum do trato gastrointestinal de seres humanos e é usado como um indicador de contaminação fecal (KEERATIPIBUL, PHEWPAN 2012). Assim, a E. coli foi utilizada neste trabalho como indicador de contaminação sanitária dos frutos. 


\section{MATERIAIS E MÉTODOS}

Como unidade amostral, foram utilizadas frutas selecionadas pelas características de maturação.

O marolo foi lavado em água corrente, descascado e fracionado em frutílhos. O morango foi lavado utilizado o pseudofruto inteiro, sem o pedúnculo.

Para avaliar a eficiência dos sanificantes estudados, foi feita a contaminação artificial das amostras com uma cultura de E. coli ATCC 25922, em Ágar BHI, em fase logarítmica de crescimento. Foi feita a suspensão do micro-organismo em $9 \mathrm{~mL}$ de solução salina, com turvação correspondente ao tubo 10 da Escala de Mac Farland, concentração aproximada de $3,0 \times 10^{9}$ de bactérias/mL.

As amostras foram dividas em blocos de 3 unidades (repetições) para sofrerem a contaminação artificial. Assim, foram colocados $300 \mathrm{~g}$ de cada fruto em recipiente estéril respectivo, contendo $1,5 \mathrm{~L}$ de solução salina, $1,5 \mathrm{~mL}$ da suspensão bacteriana e $1,5 \mathrm{~mL}$ de leite desnatado estéril, e este foi incubado em $\mathrm{BOD}$ a $5^{\circ} \mathrm{C}$ por 18 horas para viabilizar a adesão das bactérias ao alimento.

O grupo controle foi imerso em água potável apenas. Os tratamentos conduzidos foram ozônio e dicloroisocianurato de sódio (NaDCC). O tempo de contato com cada sanificante foi por 20 minutos, conforme proposto por (MAROTTA; GUIMARÃES; VEIGA, 2008).
A determinação da concentração de ozônio residual foi feita pelo método iodimétrico indireto, utilizando como solução titulante o tiossulfato de sódio a $0,005 \mathrm{~N}$ (APHA, 1992). O ozônio foi empregado a uma pressão de $1 \mathrm{kgf} / \mathrm{cm} 2$ e com vazão de 5L/min. A cuba foi saturada com ozônio por 15 minutos antes do experimento e mantida à concentração de 3,0 a 4,0mg/L de $\mathrm{O}_{3}$ durante o tratamento. O NaDCC foi aplicado na concentração de $200 \mathrm{mg} / \mathrm{L}$. A determinação da concentração de cloro residual foi feita pelo método iodimétrico indireto, utilizando como solução titulante o tiossulfato de sódio a 0,001N (APHA, 1992).

As análises microbiológicas para todas as amostras foram realizadas segundo Silva et al. (2010) e compreenderam a determinação do Número Mais Provável (NMP) de E. coli nos grupos controle e tratados.

\section{RESULTADOS E DISCUSSÃO}

Foi observada uma redução significativa, de pelo menos um ciclo logaritmo no NMP de E. coli/g do marolo artificialmente contaminado, exceto no tratamento com o ozônio. Como pode ser observado na tabela 1 .

Foi observada uma redução de cerca de 2 ciclos logaritmos no NMP de E. coli/g do morango artificialmente contaminado sanitizado com NaDCC e cerca de 1 ciclo 
logaritmo quando sanitizado com ozônio.

Como pode ser observado na tabela 2 .

Tabela 1 - Percentual de redução de E. coli em frutilhos de marolo artificialmente contaminados e posteriormente sanificados.

\begin{tabular}{lcc}
\hline \multicolumn{1}{c}{ GRUPO } & NMP de $\boldsymbol{E}$. Coli/g & Estimativa de redução E.coli $(\%)$ \\
\hline Controle* $^{*}$ & $\geq 2,4 \times 10^{3}$ & - \\
NaDCC $(\mathbf{2 0 0 m g / L )}$ & $4,3 \times 10^{2}$ & 82,08 \\
Ozônio $(\mathbf{3 , 0 - 4 , 0 m g / L )}$ & $1,1 \times 10^{3}$ & 54,17
\end{tabular}

*imersão em água potável

Tabela 2 - Percentual de redução de E. coli em morangos artificialmente contaminados e posteriormente sanificados.

\begin{tabular}{lcc}
\hline \multicolumn{1}{c}{ GRUPO } & NMP de $\boldsymbol{E}$. coli/g & Estimativa de redução E.coli (\%) \\
\hline Controle & $2,4 \times 10^{4}$ & - \\
NaDCC $(\mathbf{2 0 0 m g / L )}$ & $4,3 \times 10^{2}$ & 98,21 \\
Ozônio $(\mathbf{3 , 0 - 4 , 0 m g / L )}$ & $1,1 \times 10^{4}$ & 54,17
\end{tabular}

*imersão em água potável

Peloso et al. (2010) em seu trabalho com alface (Lactuca sativa) encontraram redução microbiana de 2 ciclos logaritmos após o uso de ozônio $(5,2 \mathrm{mg} / \mathrm{L})$ como sanificante. Veiga et al. (2003), avaliando a eficiência da água ozonizada $(0,6 \mathrm{mg} / \mathrm{L})$ contra E. coli obtiveram uma redução de 6 ciclos $\log$.

No presente trabalho, o ozônio apresentou menor redução microbiana, quando comparado ao NaDCC, fato este que pode ocorrer pela degradação pela matéria orgânica do marolo e morango. E ainda, pelo desafio que é prever como o ozônio reage com a matéria orgânica, o gás pode oxidar o composto, ou facilmente, decompor-se em oxigênio e radicais livres. A forma que ozônio se decompõe é um processo complexo, que dependem de fatores como os tipos de radicais formados em solução e o tipo de matéria orgânica presente (LANGLAIS; RECKHOW; BRINK, 1991 apud SILVA et al., 2011).

Ao mesmo tempo, o ozônio possui efeito dispersante em micro-organismos agrupados e aderidos nas superfícies de alimentos, causando um aumento virtual do número de micro-organismos. (VELANO et al., 2001 apud NASCIMENTO et al., 2008.).

A redução de E.coli no morango $(98,21 \%)$ pelo NaDCC foi superior a 356 
Alimentos (ITAL, 1997) que mostrou inativação de $91,3 \%$.

Contrastando com os resultados de Peloso et al. (2010) em seu trabalho com alface (Lactuca sativa) encontrou melhores resultados na ozonização, a sanificação com $\mathrm{NaDCC}(200 \mathrm{mg} / \mathrm{L})$ foi mais eficiente na redução da carga microbiana em marolo $(82,08 \%)$ e morango $(98,21 \%)$ se comparada a alface (64\%). Silva et al. (2003), também em alface, encontraram redução de $E$. coli de 3,69 ciclos log.

\section{CONCLUSÃO}

A partir desta pesquisa, pode-se concluir que a eficácia dos sanificantes utilizados varia com as características dos frutos utilizados, bem como o tipo de sanificante.

A redução dos de micro-organismos nas amostras de morango foi maior do que a correspondente redução no marolo.

Em relação aos sanificantes estudados e suas respectivas concentrações empregadas, concluiu-se que o NaDCC foi mais eficiente que o ozônio.

\section{Entretanto, NaDCC e ozônio} apresentam potencial para a utilização em plantas de processamento mínimo de fruto, sendo necessários estudos adicionais para obter a melhor concentração e/ou tempo de contato, otimizando assim, os resultados encontrados.

\section{REFERÊNCIAS BIBLIOGRÁFICAS}

APHA. American Public Health Association. Standard Methods for Examination of Water and Wastewater. 18 ed. Washington: APHA, 1992. 1268 p.

BRASIL. Ministério da Saúde. Agência Nacional de Vigilância Sanitária. Resolução n.150. Autoriza a inclusão do ácido dicloroisocianúrico e seus sais de sódio e potássio. Diário Oficial da República Federativa do Brasil, Brasília, 1999.

BLOCK, S. S. Disinfection, sterilization, and preservation. $4^{\text {th. }}$ ed. Philadelphia, PA: Lea \& Febiger, 1991. 1162p.

BOCCI, V. Ozone as Janus: this controversial gás can be either toxic or medically useful. Mediators of Inflamation, v. 13, n. 1, p. 311, feb. 2004. Disponível em: $<$ www.hindawi.com/getpdf.aspx?doi=10.1080 /0962935062000197083 >. Acesso em: 09 Jun. 2009.

FDA - FOOD AND DRUG ADMINISTRATION. Department of Health and Human food for human consumption PART 173. Sec.173.368. Ozone. June 2001.

FRANCO, B. D. G.; LANDGRAF, M.

Microbiologia de alimentos. 2 ed. São Paulo: Editora Atheneu, 2003.

INSTITUTO DE TECNOLOGIA DE ALIMENTOS. Teste de eficiência de Aquatabs na desinfecção de verduras e frutas. Campinas. Laboratório de microbiologia / Bayer Saúde. 1997

KEERATIPIBUL, S.; PHEWPAN, A.; LURSINSAP, C. Prediction of coliforms and Escherichia coli on tomato fruits and lettuce leaves after sanitizing by using Artificial 
Neural Networks. Food Science and

Technology. v.44, p.130-138, 2011.

KIM, J.G.; YOUSEF, A. E.; DAVE, S. Aplication of ozone for enhancing the microbiological safety and quality of foods: a review. Journal of Food Protection, v. 62, n.9, p. 1071- 1087, 1999.

MACEDO, J. A. B. et al. Cloraminas orgânicas, uma solução para evitar a formação de trihalometanos no processo de desinfecção de águas para abastecimento público. Revista de Higiene Alimentar, v. 15, n. 90/91, p. 93103, 2001.

MACEDO, J. A. B. Livro Águas e águas. $3^{\text {a }}$ Ed. Belo Horizonte: CRQ-MG., 1042p., 2007.

MAROTTA, F. C.; GUIMARÃES, L. D.; VEIGA, S. M. O. M. Avaliação da eficiência de diferentes sanificantes em morango (Fragaria Ananassa Duch) e de suas influências na vida útil do produto. Trabalho de Conclusão de curso. Faculdade de Ciências Farmacêuticas, Universidade Federal de Alfenas, Alfenas, 2008.

MELO, B., SILVA, C. A., ALVES, P. R. B. Processamento mínimo de frutas. Disponível em:

$<$ http://www.fruticultura.iciag.ufu.br/pminimo .htm >. Acesso em: 05 Fev. 2011.

NASCIMENTO, M. S.; SILVA, N.; CATANOZI, M. P. L. M. Emprego de sanitizantes na desinfecção de vegetais. Revista de Higiene Alimentar, São Paulo, v.17, n. 112, p. 42 - 46, set. 2003.

NASCIMENTO, L. C.; VEIGA, S. M. O. M.; FIORINI, J. E.; LIMA, L. C. O.; VALLE, R. H. P. Uso de derivados clorados, ozônio e ultra-som na sanificação de água e alimentos: revisão. Revista de Higiene Alimentar, São Paulo, v. 19, n. 136, p. 48-57, out. 2005.

NASCIMENTO, L. C.; LIMA, L. C. O.; PICOLLI, R. H.; FIORINI, J. E.; DUARTE, S. M. S; SILVA, J. M. S. F.; OLIVEIRA, N. M. S.; VEIGA, S. M. O. M. Ozônio e ultra- som: processos alternativos para o tratamento do café despolpado. Ciência e Tecnologia de Alimentos. v.28, n.2, Campinas, Apr./June, 2008.

PELOSO, A. G. F., CARVALHO, P. N. de, NASCIMENTO, L. C., VEIGA, S. M. O. M.; Utilização da água ozonizada e do ultrasom como sanificantes alternativos para alface (Lactuca sativa). Projeto de iniciação científica da Universidade Federal de AlfenasMG. Alfenas, 2006.

PELOSO, A. G. F., CARVALHO, P. N. de, VEIGA, S. M. O. M.; NASCIMENTO, L. C., FIORINI, J. F. Avaliação da eficiência de diferentes sanificantes em alface (Lactuca sativa) e de suas influências na vida útil do produto. Revista Higiene Alimentar. v.24, n. 180/181, p. 122-127, jan./fev. 2010.

PONCE, A.R.; BASTIANI, M.I.D.; MINIM, V.P.; VANETTI, M.C.D. Características físico-químicas e microbiológicas de morango minimamente processado. Ciência e Tecnologia de Alimentos. Campinas, v. 30, n. 1, p. 113-118, jan/mar 2010.

PRESTES, E. B. Avaliação da eficiência do ozônio como sanitizante em hortaliças folhosas minimamente processadas. 2007. Tese (Doutorado em Tecnologia de Alimentos) - Universidade Estadual de Campinas, Campinas. 2007

REIS, K. C.; SIQUEIRA, H. H.; ALVES, A. P.; SILVA, J. D.; LIMA, L. C. O. EFEITO DE DIFERENTES SANIFICANTES SOBRE A QUALIDADE DE MORANGO CV. OSO GRANDE. Ciência e Agrotecnologia., Lavras, v. 32, n. 1, p. 196-202, jan./fev., 2008.

RICE, R.G. Application of ozone in water and wastewater treatment. In: RICE, R.G. et al. Analytical aspects of ozone: treatment of water and wastewater. Chelsea, MI: Lewis, 1996. p. 7-26.

RICHARDSON, S. D. et al. Chemical byproducts of chlorine and alternative 
disinfectants. Food Technology, v. 52, n. 4, p. 58-61, Apr. 1998.

ROESLER, R. Atividade antioxidante de frutas do cerrado. Ciência e Tecnologia de Alimentos. v.27,n.1, p.5360. 2007.

SANTOS, H. P. Influência da sanificação sobre a qualidade de melão (Cucumis melo L.) minimamente processado. 2003.80 p. Dissertação (Mestrado em Ciência dos Alimentos) - Universidade Federal de Lavras, Lavras, 2003.

SILVA, N.; SILVEIRA, N. F. A.; YOKOYA, F.; OKAZAKI, M. M. OCORRÊNCIA DE Escherichia coli O157:H7 EM VEGETAIS E RESISTÊNCIA AOS AGENTES DE DESINFECÇÃO DE VERDURAS. Ciência e Tecnologia de Alimentos. Campinas, v.23, n.2, p.167-173, maio/ago. 2003.

SILVA, N.; JUNQUEIRA, V. C. A.; SILVEIRA, N. F. A. TANIWAKI M. H.; SANTOS, R. F. S.; GOMES, R. A. R. Manual de Métodos de Análise Microbiológica de Alimentos e Água. Ed. Livraria Varela. São Paulo, 2010.

SILVA, S. B.; LUVIELMO, M. M.; GEYER, M. C.; PRÁ, I. Potencialidades do uso do ozônio no processamento de alimentos.

Ciências Agrárias, Londrina, v. 32, n. 2, p. 659-682, abr/jun. 2011.

TEIXEIRA, G. H. A.; DURIGAN, J. F.; MATTIUZ, B.; ROSSI JÚNIOR, O. D. PROCESSAMENTO MÍNIMO DE MAMÃO 'FORMOSA'. Ciência e Tecnologia de Alimentos. Campinas, v.21, n.1, p.47-50, jan./abr. 2001.

TORRES, E. A. F. S. et al. Estudo das propriedades desinfetantes do ozônio em alimentos. Revista Higiene Alimentar, v. 10, n. 42, p. 18-23, 1996.

VEIGA, S. M. O. M.; Sanificação de carcaças de frango; processos alternativos.

Tese de Doutorado apresentada à
Universidade Federal de Lavras-MG. 291p. Lavras, 2003.

VEIGA, S. M. O. M.; NASCIMENTO, L. C.; CARVALHO, E. P.; CARDOSO, C. C.;

FIORINI, J. E. Eficácia da água ozonizada contra patógenos encontrados em água e alimentos. Revista Higiene Alimentar, v. 17, n. 106, p. 95-99, 2003.

VELANO, H. E. et al. Avaliação in vitro da atividade antibacteriana da água ozonizada frente ao Staphylococcus aureus. Pesquisa Odontológica Brasileira, São Paulo, v. 15, n. 1, p. 18-22, jan./mar. 2001. 